\title{
Tangatatau Rockshelter: The Evolution of an Eastern Polynesian Socio- Ecosystem. Edited by Patrick Vinton Kirch. 2017. UCLA Cotsen Institute of Archaeology Press, Los Angeles. 326 pp.
}

\author{
Maureece J. Levin ${ }^{1 *}$ \\ ${ }^{1}$ Archaeology Center, Stanford University, Stanford, USA. \\ *mjlevin@stanford.edu
}

Received August 1, 2018

OPEN ठ ACCESS

Accepted September 21, 2018

DOI 10.14237/ebl.9.2.2018.1371

Copyright (C) 2018 by the author(s) licensee Society of Ethnobiology. This is an open-access article distributed under the terms of the Creative Commons Attribution-NonCommercial 4.0 International Public License (https://creativecommons.org/licenses/by-nc/4.0), which permits non-commercial use, distribution, and reproduction in any medium, provided the original author and source are credited.

In the late 1980s and 1990s, archaeologist Patrick Kirch and his interdisciplinary team conducted fieldwork on Mangaia, the southernmost of the Cook Islands in Eastern Polynesia. Much of this work centered on the Tangatatau Rockshelter, which has an exceptionally rich archaeological record. While they published most of this research in scholarly journals in the 1990s, the volume reviewed here represents a comprehensive final report of the research. Furthermore, with nearly three decades of perspective, the report presents not only initial analyses, but also considerable reanalysis of the original research on Mangaia, in light of theoretical and methodological advances.

Kirch and his colleagues present their work in a standard archaeological site report format, including introduction and background (three chapters), data and analysis in considerable detail (ten chapters), ending with an island chronology and some broader synthetic conclusions (one chapter). The introductory chapters are written in an approachable, almost chatty style, peppered with personal anecdotes that bring the process of doing field archaeology to life. Mangaia has a unique geology, with a very old, almost circular central volcanic core, surrounded by continuous upraised coral. These physical factors have led to inland adaptations by humans, as well as use of a plethora of caves and rockshelters.

The dating of human settlement of Mangaia has been a point of contention in the past. Debates within Pacific Islands archaeology on the timing of settlement began soon after the Mangaia fieldwork; the application of chronometric hygiene and AMS dating technology to sites in East Polynesia pointed toward considerably later settlement than many researchers had previously argued. Although Kirch initially was skeptical of these changes, he did come around to accepting the weight of the evidence. His straightforward discussion of this change, and the dating issues that still remain for Mangaia, truly represent what the internal correction mechanisms of evidence-based research should look like. At this time, humans appear to have settled the island approximately 1000 years ago.

As is typical of Kirch's work, the analysis and interpretation of archaeological materials leans towards human adaptations to island environments. The level of detail in some chapters, which is de rigueur for specialist reports and essential for reproducibility, may be tedious for non-specialists who are not particularly interested in the texture and color of soil layers or the criteria used for species identification. In this sense, it is not an ideal read for a popular audience or introductory class. However, this is also not the intended purpose. For archaeologists in ethnobiological specializations like zooarchaeology and archaeobotany, it is useful to get this level of detail in a work that also treats a single site so broadly.

Three chapters from multiple authors deal with faunal material recovered from the site: one chapter each for vertebrates (other than fish), fish, and invertebrate remains (primarily, but not exclusively, mollusks). Virginia Butler's fish photographs are large and exceptionally clear, which is likely to make her chapter interesting and useful for ichthyoarchaeologists. Only one chapter is devoted to plant remains. 
Given that the described collection of archaeobotanical materials was not particularly systematic, which was typical for archaeological work at the time in the Pacific, this seems appropriate. Even still, the team did recover a plethora of plant remains resulting in a number of insights about terrestrial plant food production and non-food use of plants such as candlenut (Aleurites moluccana). Here, too, the photographs are by-and-large fantastic.

Three chapters deal with the abundant artifactual remains from the rockshelter, an assemblage dominated by shell fishhooks and adzes; the latter two of the artifact chapters deal with each of these two classes of artifacts individually. One final data chapter covered the other sites located and excavated during fieldwork in brief. While Tangatatau Rockshelter had the most persistent occupation of any site studied during fieldwork, these other sites place Tangatatau and its assemblage in a broader Mangaian context. Notably, one site contains evidence of a large amount of human remains in a clear midden context, consistent with ethnohistoric discussions of cannibalism.

The final chapter discusses the sequence and broader implications, both in Mangaian and Eastern Polynesian context. Although the proposed phases of settlement are artificial, the use of site names rather than descriptive English words to name the phases helps to avoid overinterpretation, a point that Kirch explicitly discusses. The synthesis examines the stresses of human activity on the old volcanic island. Notably, older volcanic islands tend to have lower levels of soil nutrients, which has contributed to the vulnerability of Mangaia's ecosystems. Early in the island's settlement, there was widespread deforestation of the endemic forests as humans engaged in horticultural practices and extirpated bird species and the Pacific flying fox (Pteropus tonganus). These pressures may have been what prompted Mangaians to remove pigs from the island and also could be related to the interpersonal violence apparent in the human remains in a midden. Types of marine resources used changed over time as well. The interconnectedness of environmental and social shifts are examined in detailed narrative form.

The quality of the printed hardcover book is excellent and the coated paper works well with its image-laden content. It is unclear why, with this level of production quality, all the images are greyscale or black-and-white. Nevertheless, even the greyscale photographs help to bring the process of doing archaeology to life. Overall, this volume is an excellent example of synthetic, multi-proxy analysis in environmental archaeology. It is a worthwhile addition to a book collection for any ethnobiologist interested in diachronic analysis of human adaptations to insular environments. 